\title{
Un caso de Tinea unguium producido por Microsporum gypseum (Bodin, 190\%) Guiart et Grigorakis, 1928.
}

\author{
por \\ Armando Ruiz * \\ (Recibido para su publicación el 2 de mayo de 1993)
}

Es opinión general que las especies del género Microsporz:m se limitan a atacar tan sólo la piel y el pelo, como señalan CONANT y colaboradores (1). Tanto SwarTz (5) como Lewis y Hopper (3), no incluyen las especies de est género como agentes etiológicos de onicomicosis. Sin embargo, VuillzMIN (6) al hablar de onicomicosis dice lo siguiente: ...."Le Microsporum Audouini est déja signalé par Bazin dans l'ongle "faisant brosse". Rabello y trouve á Rio de Janeiro le M. lanosum...". FALCHI (2) describe un caso de onicomicosis acompañado de una tiña microspórica del cuero cabelludo, aislando tanto del pelo como de la uña el Microsporum lanosum, y señala, entre los puntos interesantes de este caso, la localización ungular poco común de los Microspora.

Nosotros tuvimos la oportunidad de observar un caso de Tinea unguium, de la cual hemos aislado el Microsporum gypseum.

A mediados de Noviembre del año pasado se presentó una paciente (M.A.) q̣ue mostraba en la uña del dedo pulgar de la mano izquierda una porción descolorida en la extremidad próximal y hacia el borde lateral izquierdo. Al hacer el raspado de dicha zona se notó que era friable y, removidas las primeras capas, se encontró un cúmulo de detritos. Una parte del material obtenido por raspado se montó entre porta y cubreobjetos en solución de $\mathrm{NaOH}$ al $10 \%$ y se procedió al examen microscópico, el que reveló la presencia de un abundante micelio septado y ramificado, quedando así patente la naturalcza micótica de la lesión. Es interesante el hecho de que la infección comenzara en la extremi-

- División de Parasitología, Laboratorio Bacteriológico, Hospital San Juan de Dios. 
Fig. 1: A la derecha, Microsporum gypseum, colonias pulverulentas en un medio en estudio. A la izquierda, M. gypseum, colonias algodonosas, Sabouraud glucosado.

Fig. 2: Uña del dedo pulgar de la mano izquierda mostrando el aspecto actual de la lesión.

Fig. 3: Macro y microconidias de M. gypseum. Sabouraud glucosado en tubo. Cloral lactofenol. Contraste de fases. $200 \times$.

Fig. 4: Macro y microconidias del M. gjpseum. Sabouraud glucosado en tubo. Cloral lactofenol. $450 \times$.

Fig. 5: Macro y microconidias de M. gypseum. Sabouraud glucosado en tubo. Cloral lactofenol. Contraste de fases. $450 \times$.

(Fotos y microfotos A. Trejos) 


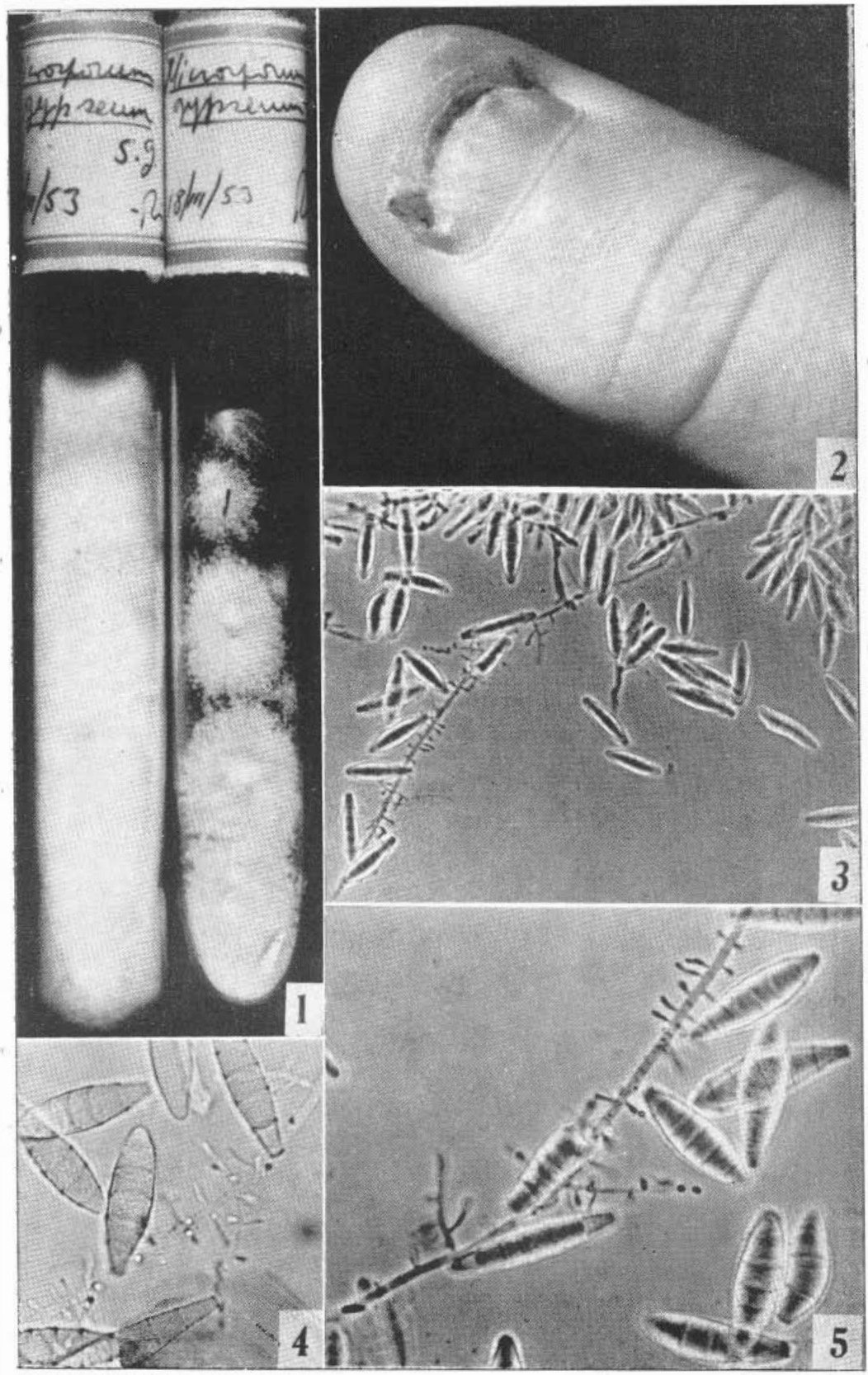


dad proximal de la uña, lo que es raro en estas micosis. La lesión siguió extendiéndose hacia el borde lateral derecho hasta alcanzarlo en pocos días, quedand: así el resto de la uña separado de la raíz. Mes y medio después la uña estaba afectada en su totalidad, lo que determinó la caída de la misma. La uña que nació luego está deformada, descolorida y engrosada, cuyo aspecto actual se puede observar en la Fig. 2. Es importante hace- notar que ninguna de las otras uñas está afectada y que la paciente no ha mostrado lesión dermatofítica alguna en el resto del cuerpo.

Por cultivo de fragmentos de uña en medio de Sabouraud glucosado pudimos aislar el dermatófito causante de la infección. Trasplántado a terreno fresco presenta un crecimiento más o menos rápido, formando una colonia pu\}verulenta, color crema pardusco con ligeros tintes rojizos (Maerz y Paus. 10-E-4) (4). En los siguientes repiques la colonia toma un coior crema(MAERz y Paul 9-D-2) (4) y un aspecto menos pulverulento, formándose partes algodonosas y blanquecinas (Fig. 1). El reverso de la colonia es de un color pardo anaranjado con zonas más rojizas. Microscópicamente se obscrvan numerosas macroconidias elipsoidales, multiseptadas, con dos a ocho divisiones, predominando las de cuatro a seis. Miden de 23 a 65 micras de largo por 6,3 a 12,6 micras en su parte más ancha y están recubiertas de una membrana fina casi lisa (Fig. 3, $4,5)$. Se pueden encontrar también microconidias unicelulares y claviformes (Fig. 3, 4, 5), clamidosporas y algunas hifas en raqueta y pectinadas.

En base de la anterior descripción hemos considerado al dermatófito aislado como Microsporum gypseum (Bodin, 1907), Guiart et Grigorakis, 1928.

\section{RESUMEN}

El autor describe un caso de onicomicosis producido por Micrespornit gypseum (Bodin, 1907) Guiart et Grigorakis, 1928. El hallazgo se consider: de interés, ya que las especies del género Microsporum muy zaramente han side aisladas de casos Tinea unguium.

\section{SUMMARY}

The author describes a case of onychomycosis by Micresperum gypsezmin (Bodin, 1907) Guiart et Grigorakis, 1928. The case is of interest since the species of the genus Microsporum have raraley been found causing Tinea ning guium.

\section{RIASSUNT}

L' Autore descrive un caso di onicomicosi prodotto da! Micresporum? gypseum (Bodin, 1907) Guiart et Grigoraki, 1928.

La scoperta si considera di grande interesse dato che le specie del genete Microsporum raramente si é potuto isolarle da casi di Tinea wnguinm. 


\section{BIBLIOGRAFIA}

1. Conant, N. F., D. S. Martin, D. T. Smith, R. D. Baker, J. L. Callaway.

1948. Manual de Micologia Clinica, $1^{3}$ Ed. XIX $\times 456$ pp. M. V. Fresneda (Editor). La Habana, Cuba.

2. FALCHI, G.

1929. Micosi del cuoio capelluto e delle unghie in adulto da "Microsporum lanosum". Riun, Sez. Lombarda-Ligure Soc. Ital. dermat e sifil., 16 p. 2 pl. Res. in Bol. Inst. Patsteur 28 (30):1001, 1930.

3. LEwIS, G. M. \& M. E. Hopper.

1948. An Introduction to Medical Mycology, $3^{a} \mathrm{Ed}$. XV $\times 366$ pp. The Year Bcok Company, Inc. Chicago.

4. Maerz, A. \& M. R. Paul.

1950. A Dictionaty of Color, 2 Ed. VII $\times 208$ pp. McGraw-Hill Book Company, Inc. New York.

5. SWARTZ, J. H.

1949. Elements of Medical Mycology, $2^{2}$ Ed. XIX $\times 240$ pp. Grune \& Stratton, New York.

6. Vuillemin, P.

1931. Les Champignons Parasites et les Myroses de l'Homme, 290 pp. Paul Lechevalier \& Fils, París. 